\title{
SOBRE LA CONFIGURACIÓN ESTRÓFICA DE LA RIMA CASTELLANA
}

1. Dentro del sistema rítmico de la lengua castellana, el recurso expresivo de la rima tiene como nota constante y esencial la repetición del timbre articulatorio de uno o más fonemas, vocales o consonánticos ${ }^{1}$. Este fundamental carácter de reiteración articulatoria hace que la rima se dé normalmente, en castellano, en el marco estructural de la estrofa, ya que sólo muy raramente se puede documentar en la métrica española la repetición de timbres articulatorios en el ámbito melódico de un solo verso ${ }^{2}$.

2. Sin embargo, los estudios más numerosos y detallados sobre la rima castellana se han venido dedicando a su estructura y localización en el espacio rítmico del verso, con abstracción -y tal vez olvido- del oficio y localización estrófica de la rima. Estimo que podría ser oportuno intentar el bosquejo de un cuadro en que se recogiesen los rasgos más generales de la relación estrofa/rima.

3. La rima, al insertarse en la cadena rítmica castellana ${ }^{3}$, no se configura por la mera repetición inorgánica de uno o varios timbres articulatorios, sino que -en el uso general- las articulaciones reiteradas para constituir el núcleo rimante requieren la constante concurrencia del acento intensivo propio de un vocablo lleno o semilleno y la contigüidad - con leves excepciones- de una pausa rítmica. Esstas dos notas determinan con

1 Cf. Balbín, RAFAel DE, Sistema de rítmica castellana. Madrid, 1962, pág. 219.

2 Las distintas modalidades de la rima en eco demuestran la escasa eufonía que alcanza en castellano, la reiteración de un mismo núcleo reinante en un mismo verso.

3 Cf. Balbín, Sistema..., pág. 250. 
toda claridad el paso de la mera aliteración a lo que constituye propiamente la rima. La riqueza y complejidad en la estructura del núcleo fónico que se reitera le presta una gran fuerza impresiva y hace de la rima buen instrumento para dar relieve en el ámbito atencional del oyente, a los efectos expresivos destacados en el decurso de la cadena hablada.

4. Con todo, la capacidad expresiva de la rima dimana esencialmente de su índole reiterativa. De modo análogo a como la repetición de los lexemas o vocablos completos, constituye un recurso para intensificar el valor comunicativo de las significaciones (en anáfora, epanadiplosis, pleonasmo), así la reiteración de factores fonológicos (acento intensivo, pausa, timbre articulatorio) refuerza la expresividad en la cadena rítmica. Tanto en la percepción sensible como en los procesos psíquicos de la memoria y de la atención, la repetición de los fenómenos origina efectos generales de intensifieación. La repetición equivale a intensidad 4 Y los hechos lingüísticos no señalan excepción en estos principios psicológicos generales. La percepción repetida y la atención reiterada, al multiplicar la relación entre el hombre y los seres que le rodean, hacen que la vivencia humana se haga más honda y matizada.

\section{II}

5. La rima castellana es un hecho fonológico de reiteración, y por ello resulta necesariamente un recurso estilístico intensivo. Aparece siempre dentro de la estrofa castellana; pero las formas de configurarse la rima, en el conjunto estrófico, son muy numerosas y variadas, y marcan en su diversidad grados y modos diferentes de intensificación impresiva.

Con relación a la estrofa, la repetición del núcleo rimante puede referirse :

a) A la proporción en que se reiteran los núcleos rimantes, dentro de las fronteras de la estrofa.

b) A la ubicación de la rima dentro del ámbito estrófico.

c) Al intervalo métrico que media entre los núcleos rimantes reiterados.

6. La estrofa en castellano se constituye al configurarse como período rítmico la cláusula sintáctica castellana, integrada por una o varias oraciones gramaticales. $\mathrm{Y}$ las fronteras rítmicas de la estrofa vienen siempre a coincidir con los límites estructurales de la cláusula sintáctica ${ }^{5}$.

4 Cf. Fröbes, José, Tratado de Psicología experimental. Madrid, 1944, t. II, página 88.

5 Cf. BaLbín, Sistema..., págs. 34-35. 
7. Por la proporción en que aparece reiterada en una estrofa, la rima castellana puede ser :

a) Rima densa, si se construye en todos los grupos melódicos o versos, que se integran en la unidad estrófica, como en

¿Rosaleda de oro,
selva del sonoro
ruiseñor del coro!

R. del Valle-Inclán'

Ya se ríen estas fuentes, y son perlas las que fueron lágrimas, con que sintieron esas estrellas ausentes;

y a las aves, sus corrientes hacen instrumentos claros, con que quieren celebraros. Todo se anticipa a veros, $y$ todo intenta ofreceros con lo que pueda alegraros.

Lope de Vega ${ }^{7}$

b) Rima suelta, aquella que sólo se da en algunos versos de la estrofa, pero no en todos ellos, así en

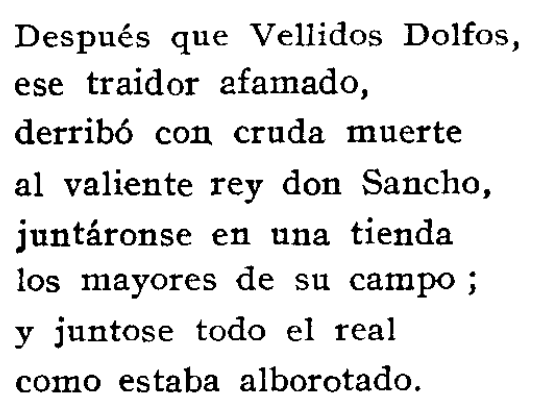

Romance fronterizo

- Cf. Valle-Inclán, R. de, Claves líricas. Madrid, 1930, pág. 95.

7 Cf. VEGA, LoPe DE, La dama boba. Ed. F. Tolsada. Zaragoza, 1955, pág. 69.

- Cf. Primavera y flor de romances, edición de M. Menéndez y Pelayo, en $A$ n. tología de poetas líricos castellanos. Madrid, 1910, t. VIII, págs. 88-89. 
Es mi amor, dueño mío, como la sombra; mientras más apartad, más cuerpo toma. Que ausencia es aire, que apaga el fuego chico $\boldsymbol{y}$ aviva el grande.

Bolero popular,

c) Rima cero, si ninguno de los versos que componen la estrofa lleva rima, como en

De esta felicidad al sobresalto con que en las cortes míseras se vive, ¿cuánta no es la distancia? Aquí la vida en curso fácil y risueño pasa, dejando en pos recuerdos deliciosos...

El duque de Ahumada ${ }^{10}$

8. E1 grado de intensidad expresiva de estos tres módulos estróficos, se manifiesta en los pasajes más arriba consignados como claramente distinto. En los textos de R. del Valle-Inclán y Lope de Vega, la tupida y apretada reiteración de la rima sirve de instrumento de expresión vivencial muy fuerte, $\mathrm{y}$ a un estilo rítmico culto y personal. El romance fronterizo y el bolero popular, con la configuración de la rima suelta, da a la estrofa una expresividad moderada y serena, como vinculada a referencias narrativas, donde predominan factores objetivos; $\mathrm{y}$ vertidas en formas estilísticas populares. En tanto que el pasaje del duque de Ahumada muestra con el uso de la rima cero una expresión comunicativa más débil, como correlativa en este fragmento, de finalidades literarias demostrativas y noéticas.

9. La configuración más característica de la rima densa, aunque no quizás la más armoniosa, la constituye en castellano el tipo de la monorrima, como en

Tomá fruta, mi señora, fresca y cogida de agora.

\section{Distico popular 11}

- Cf. Cuentos y poesias populares andaluces, coleccionados por Fernán CabaUlero. Sevilla, 1859, pág. 290.

10 Cf. Poetas líricos del siglo XVIII. Ed. de L. A. Cueto, B. A. E., t. III, página 707.

11 Cf. CoRreas, Gonzalo, Vocabulario de refranes y frases proverbiales. Madrid, 1924, pág. 484. 
Besome el colmenero

y a la miel me supo el beso.

Dístico popular 12

Exié de la fontana una blanda frior, de la sombra del árbol un temprano sabor; dava el arvolorio sombra e buena olor, semejava que era huerto del Criador.

\section{Juan Lorenzo de Astorga 13}

Tiemblan los lirios tempranos

y los árboles lozanos

al contacto de esas manos.

Rubén Dario 14

Con sayal de amarguras, de la vida romero, topé tras luenga andanza con la paz del sendero. Fenecía del día el resplandor postrero.

En la cima de un álamo sollozaba un jilguero.

$$
\text { R. Pérez de Ayala is }
$$

El dístico con rima, o pareado, es la forma de monorrima más frecuente y característica de la métrica popular, y su fuerza expresiva - singularmente en los versos menores- es tan grande que muy a menudo estos dísticos pareados han servido de apoyo y estrofa germinal — con el nombre de estribillo- para más anchos desarrollos rítmicos y poemáticos.

10. En las restantes estrofas copiadas en el párrafo anterior, todos los grupos melódicos riman también, y el núcleo rimante está compuesto en todas las reiteraciones melódicas por los mismos fonemas y dispuestos en idéntico orden. El texto de Juan Lorenzo de Astorga y el de R. Pérez de Ayala repiten en sendas estrofas tetraversales la rima aguda (-or) o grave (-ero), pero mantenida en todos y cada uno de los versos. La misma reiteración - llevada a su número máximo dentro de los límites de la estrofa- aparece en Rubén Darío, con la sola diferencia de que el núcleo rimante, por insertarse en estrofa triversal, alcanza solamente una triple

12 Idem, pág. 82.

13 Cf. Poesía de la Edad Media y poesía de tipo tradicional Ed. de D. Alonso. Buenos Aires, 1942, pág. 81.

14 Rubén Darío, Poesías completas. Ed. de A. Méndez Plancarte. Madrid, 1952, página 740 .

15 Cf. Pérliz de Ayala, Ramón, Poesías completas. Buenos Aires, 1944, pág. 17. 
consignación. Esta configuración monorrima, en estrofas de más de dos versos, por su propia y extrema concentración intensiva, aparece en castellano en autores cultos especialmente, y en períodos literarios de acentuada conciencia personal del estilo.

11. La vigorosa expresividad de la rima densa se conserva en la que podría denominarse polirrima, y registra entre sus modalidades estructurales la que llamaré dirrima, por ser dos — distintos y diferenciados- los núcleos rimantes que se combinan en la construcción de la estrofa. Pero es indudable que lo que gana el conjunto estrófico en variedad y armonía se traduce en relajación de intensidad expresiva por la disposición rítmica de la dirrima. Así en

Sácame de esta cadena, que recibo muy gran pena, pues tu tardar me condena. Carcelero, no te tardes que me muero.

\section{Juan del Encina 16}

Aquí penitencia hacemos, y sólo yerbas comemos, y a veces nos acordamos, de lo mucho que dejamos por lo poco que tenemos.

Tirso de Molina 17

Algunos años pasaron, $y$ el enero cubre con manto severo, las flores que perfumaron el sendero que las vírgenes cruzaron.

\section{Enrique Gil 18}

Pasó por el mundo al paso de una espera de sosiego, y fué a acostarse - sin fuegoen dulce luz del ocaso.

M. de Unamuno 19

16 Cf. Poesía de la Edad Media..., págs. 284-285.

17 Cf. Trrso DE Molina, El condenado por desconfiado. Ed. A. González Palencia. Zaragoza, 1952, pág. 24.

18 Cf. Gil, Enrique, Poesías líricas. Madrid, s. a., pág. 112.

19 Cf. Unamuno, M. DE, Antología poética. Ed. de L. F. Vivanco. Madrid, 1942, página 437. 
La prueba del trío, la prueba del fuego...

¡Cómo ha salido mi corasonsiyo

del mejor acero!

Manuel Machado 20

La dirrima, como construcción estrófica en que se combinan y reiteran solamente dos núcleos rimantes diferenciados, es probablemente la forma de más numeroso empleo en castellano. Aparece con más frecuencia en estrofas tetraversales y pentaversales de rima total, como en los textos de J. del Encina, Tirso de Molina y M. de Unamuno; pero también se encuentra usada en conjuntos estróficos configurados con rima vocálica, como ocurre en el pasaje de M. Machado. El fragmento poemático de E. Gil recoge la configuración de la dirrima en estrofas de más de cinco versos, fórmula rítmica no imposible, pero sí muy poco frecuentada.

12. Formas de más variada reiteración timbral aparecen también en el sistema estrófico castellano, especialmente a partir de las unidades hexaversales. Entre estas formas está la que pudiera llamarse trirrima, por estribar en la reiteración de tres núcleos rimantes distintos, como en:

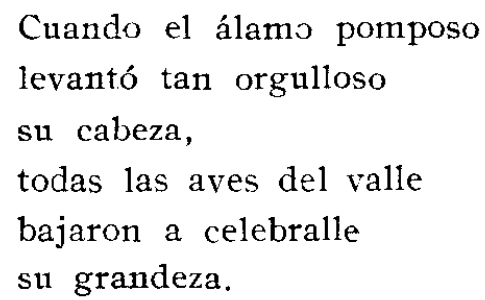

\section{J. Zorrilla 21}

Bella es tu juventud en sus albores como un campo de rosas del Oriente; al ángel del recuerdo pedí flores, para adornar tu sien, y me las dió ; yo decía al ponerlas en tu frente: sé más feliz que yo.

Juan Arolas 22

20 Cf. Machado, Manuel, Poesía. Madrid, 1942, pág. 202.

21 Cf. Zorrilita, Josí, Obras completas. Valladolid, 1943, t. I, pág. 43.

22 Cf. Las cien mejores poesías líricas de la lengua castellana. Ed. de M. Menéndez y Pelayo. Madrid, 1925, pág. 277. 
Bajemos al campo; tumulto de plumas, parece el arroyo de blancas espumas que quiere, cantando, correr y saltar; su airosa mantilla de fresca neblina terció la montaña; la vela latina de barca ligera se pierde en el mar.

\section{Gutiérrez Nájera ${ }^{23}$}

Bien como la flama ardiente, que tus çentellas envía en torno, de continente de sus ojos parescía que tus rayos desparçía a do quier que reguardava, y fuertemente turbava a quien menos lo temía.

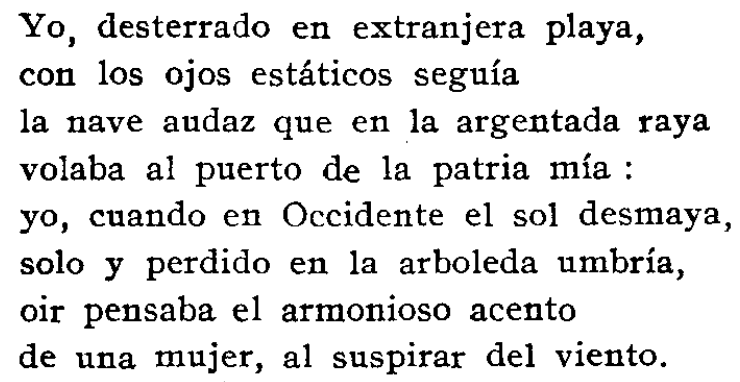

J. de Espronceda ${ }^{25}$

En los poemas de J. Zorrilla, J. Arolas y M. Gutiérrez Nájera la construcción hexaversal de la estrofa hace que la trirrima configure un tipo de reiteración elemental y sencillo, con solos dos núcleos rimantes en cada ámbito estróíco, o sea con la repetición mínima para que se constituya la rima. Expresividad bien diferenciada alcanza la trirrima en las estrofas octoversales, porque tanto en el texto medieval del marqués de Santillana, como en el moderno de J. de Espronceda, junto a la duplicación de algunos núcleos rimantes (-ente, -ava, -ento), se triplican otros núcleos (-aya, - $\{a$ en Espronceda) y se cuatriplica -ía en Santillana.

$2 s$ Cf. Antología de la poesía española e hispanoamericana. Ed. Federico de Onís. Madrid, 1934, pág. 12.

24 Cf. Cancionero del siglo XV. Ed. de R. Foulché-Delbosc. Madrid, 1912, t. I, página 545.

25 Cien mejores poesias, pág. 234. 
13. E1 mayor número absoluto de reiteraciones rimantes dentro de t1na sola estrofa lo alcanzan en castellano las combinaciones rítmicas que llamamos décima y soneto. Así en

Una noche, una de aquellas noches que alegran la vida, en que el corazón olvida sus dudas y sus querellas; en que lucen las estrellas cual lámparas de un altar; $y$ en que convidando a orar la Iuna como Hostia Santa, lentamente se levanta sobre las olas del mar.

G. Núñez dé Arce $\mathbf{2 6}$

i Beato sillón! La casa corrobora su presencia con la vaga intermitencia de su invocación en masa a la memoria. No pasa nada. Ios ojos no ven : saben. E1 mundo está bien hecho: el instante 10 exalta a marea, de tan alta, de $\tan$ alta, sin vaivén.

De amenazas del Ponto, rodeado, $y$ de enojos del viento, sacudido, tu pompa es la borrasca, y su gemido más aplauso que te da que no cuidado. Reinas con majestad, escollo osado, en las iras del mar enfurecido, $\mathbf{y}$, de sañas de espuma encanecido, te ves con tus peligros coronado. Eres robusto escándalo a orgullosa prora, que por peligros naufragante, te advierte, y no te toca, escrupulosa. $\mathrm{Y}$ a su envidia y al mar, siempre constante, de advertido bajel seña piadosa eres norte $\mathrm{y}$ aviso a vela errante.

Francisco de Quevedo 28

-6f. NúÑ̃z de ARCE, Gaspar, Obras escogidas. Barcelona, 1911, pág. 144.

27 Cf. Poesía española. Ed. de Gerardo Diego. Madrid, 1932, pág. 206.

28 Cf. Quevedo, Francisco DE, Obras completas. Ed. J. M. Blecua. Barcelona, 1963, pág. 83. 
Los textos de G. Náñez de Arce y de J. Guillén se configuran con cuatro núcleos rimantes distintos, y la estrofa de $\mathrm{F}$. de Quevedo se construye también como tetrarrima. Pero aparte de que la décima en Núñez de Arce y en Guillén se forma con versos menores y el soneto quevedesco mediante versos mayores ${ }^{29}$, su expresividad es distinta por el diferente número de grupos melódicos que forma cada una de las unidades estró ficas. La descripción natural y directa en $\mathrm{N}$. de Arce, y abstractiva en Guillén, al igual que el sentencioso poema de Quevedo, cristalizan en la gravedad expresiva de la estrofa larga ${ }^{30}$; aunque el último de los pasajes parece asentar una intensidad comunicativa mayor sobre la reiteración triple de -ado, -ido y doble de -osa, -ante. N. de Arce reitera tan sólo una vez -ida, -anta y dos veces -ella, -ar, mientras que Guillén repite -encia y -alta una vez y dos veces -asa y -én.

RAFAEL, DE BALBÍN

20 Cf. Balbín, Sistema..., pág. 44, n. 8.

so Cf. Idem, pág. 275. 